\title{
Short story The Root of All Evil Грэма Грина: жанр и поэтика Short Story The Root of All Evil by Graham Greene: Genre and Poetics
}

\author{
Махмуд Мохаммед Алатея ${ }^{1}$ \\ Mahmoud Mohammed Al Ateya \\ ${ }^{1}$ Petro Mohyla Black Sea National University \\ 10, 68 Desantnykiv Street, Mykolaiv, 54003, Ukraine
}

DOI: $10.22178 /$ pos.38-4

LCC Subject Category: PR6000-6049

Received 01.08.2018

Accepted 10.09.2018

Published online 18.09.2018

Corresponding Author: mikhilevaleks@gmail.com

(c) 2018 The Author. This article is licensed under a Creative Commons Attribution 4.0 License (c) (1)
Аннотация. Статья рассматривает проблему жанровой атрибуции short story The Root of All Evil Грэма Грина, которую именуют то новеллой (французская критика), то рассказом (русскоязычная критика), и взаимосвязь ее поэтики с жанровой моделью. Важность и актуальность решения поставленной задачи заключается в том, что это первое исследование жанровой специфики и поэтики одной из гриновских short stories, написанных в комическом модусе, которое открывает перспективу комплексного изучения всего корпуса его малой прозы (до сих пор не изученной).

Исследование опирается на теорию жанра (М. Бахтин, Н. Лейдерман, Р. Уэллек и 0. Уоррен и др.), согласно которой жанр является формой художественного познания мира, обладает жанровой памятью (семантическим ядром жанра) и задает параметры художественного миромоделирования и прочтения текста, а также использует генологические, текстологические, структурноаналитические и нарратологические принципы анализа, что позволило сделать следующие выводы. Во-первых, наличие в произведении таких характерных для жанра новеллы признаков, как необычное происшествие или "казус», лежащие в основе сюжета; одна доминирующая сюжетная линия и динамизм развертывания событий с их аккумуляцией; неожиданный сюжетный поворот (новеллистический пуант) и комическое начало, присущее значительному количеству новелл. Во-вторых, смысловое содержание произведения отвечает художественной модели именно новеллистического жанра, для которой характерно осмеяние недолжного, ущербного, ложного (в данном случае религиозного догматизма) и утверждение здоровой и полноценной стихии бытия.

Использованная в работе методика и полученные результаты представляются перспективными как для дальнейшего изучения малой прозы Грэма Грина, так и для аналогичных сфер исследования.

Ключевые слова: Грэм Грин; short stories; новелла; рассказ; миромоделирование; комический модус.

Abstract. The article considers the problem of genre attribution of the short story The Root of All Evil by Graham Greene, which is defined as novella by the French criticism and as a story by the Russian criticism, and correlation of its poetics with the genre model. The importance and topicality of solving this problem lies in the fact that this is the first study of the genre specificity and poetics of one of Greene's short stories written in the comic mode, which opens the prospect of a comprehensive study of the whole body of his short prose (not studied yet).

The research is based on the theory of the genre (M. Bakhtin, N. Leiderman, R. Welleck and 0 . Warren, etc.), according to which the genre is a form of artistic cognition of the world, has genre memory (the semantic core of the genre) and sets the parameters of the artistic world-modeling and reading of the text, and also uses the genological, textual, structural-analytical and narratological principles of analysis, which allowed to make the following conclusions. First, the presence in the work of such characteristic features of the novel genre as an unusual case or incident 
underlying the plot; one dominant storyline and the dynamism of unfolding of events with their accumulation; an unexpected turn of the plot (novelistic pointe) and a comic beginning inherent in a significant number of short stories. Secondly, the semantic content of the work corresponds to the artistic model of the novelistic genre, which is characterized by a mockery of the undue, defective, false (in this case religious dogmatism) and the assertion of a healthy and full-fledged element of being.

The method used in the work and the results obtained are promising both for further study of Graham Greene's small prose and for similar fields of research.

Keywords: Graham Greene; short stories; novella; story; world-modeling, comic modus.

\section{ВВЕДЕНИЕ}

Выдающийся английский романист XX века Грэм Грин (1904-1991) был одновременно и блестящим мастером малой прозы - short stories. Однако эта сторона творчества великого писателя, без которого, как верно заметил В. Бибихин, «литературу XX века уже нельзя представить» [1], практически не привлекает внимание исследователей. Если о гриновских романах написаны десятки монографий и диссертационных исследований, то о его малой прозе имеются лишь общие суждения [5, cov.; 4, cov. 4], предисловия к некоторым сборникам short stories [8, с. 5-9; 10, c. 3; 7, с. 7-12; 11] да краткие издательские справки, предваряющие переводы [2, с. 2; 3, c. 2]. Это касается как англо-американской, западной, так и советской/постсоветской литературной критики.

Об этой ситуации хорошо сказал сам Грин. В предисловии к сборнику своей малой прозы Collected stories (1972), который содержал тридцать восемь произведений, Грин писал: «Сегодня, когда этот толстый том лежит передо мной, я начинаю понимать, что с первых дней своей деятельности я был по сути дела автором рассказов, - они вовсе не «клочки», какими я их раньше считал. И все-таки, хотя многие из рассказов, представленных в этом томе, может быть, лучшее из того, что я когда либо писал, меня воспринимают как романиста, который иногда писал рассказы, так же как некоторые новеллисты (Мопассан, В. Притчет) «иногда писали романы» [9].

На сегодняшний день его перу принадлежит более пятидесяти произведений этого жанра: английское название Complete short stories (2005) [6] содержит 53 произведения, а издание гриновских переводов малой прозы на французский язык под названием Nouvelles completes (2013) [7] насчитывает 54 за счет включения отсутствующего в английском издании рассказа The Stranger's Hand (1949).

Обращает на себя внимание разнобой в жанровой дефиниции гриновских short stories при переводе их на другие языки. Так, в частности, во французских переводах они обозначены как «новеллы», а в критике называются то «новеллами», то «рассказами»; в русских как «новеллы» или «рассказы», в украинских - как «рассказы».

Эта жанровая неопределенность таит в себе опасность неадекватного понимания их идейно-смыслового и эстетического содержания. Ведь жанровая форма, если исходить из теории жанра (М. Бахтин, Р. Уэллек и О.Уоррен, Н.Лейдерман, Т. Бовсунивская и др.), - это модель, которая задает присущие данному жанру параметры мировосприятия и художественного воспроизведения. В силу этого определение жанровой принадлежности является основополагающей исследовательской задачей при изучении всего корпуса short stories Грэма Грина.

По предварительной оценке к новеллистическому жанру малой прозы писателя можно отнести более 20 произведений, большинство из которых несет на себе явный отпечаток комизма. Одной из наиболее ярких среди них по богатству оттенков комического и мастерству сюжетно-композиционного построения с полным основанием можно назвать новеллу The Root of All Evil («Корень зла»), впервые опубликованную в 1964 году в мартовском номере лондонского журнала New Statesmen (во французском издании датируется 1967 г).

Цель работы - доказать, что это именно новелла, а не рассказ и показать, как жанровая новеллистическая модель формирует соответствующий художественный мир, доминантой которого в данном случае является стихия комического. 
Значимость и актуальность постановки этой проблемы заключается в том, что это первое исследование жанровой специфики и поэтики одной из гриновских short stories, написанных в юмористическом модусе, которое открывает перспективу комплексного изучения всего корпуса его малой прозы (до сих пор практически не изученной).

Для достижения поставленной цели использованы генологический, текстологический, структурно-аналитический методы и нарратологическая методика.

\section{РЕЗУЛЬТАТЫ ИССЛЕДОВАНИЯ}

В работе мы опираемся на дефиницию новеллистического жанра, нашедшего отражение в книге «Теория литературных жанров» [12]. Согласно трактовке авторов данной книги, новелла представляет собой канонический жанр малой прозы, для которого характерны концентрированность и динамизм сюжета, восходящего, как правило, к анекдоту и притче; установка на «казус - странный случай текущей современности или удивительный исторический факт» [12, с. 59]; наличие резкого сюжетного слова или пуанта «финальной перемены точки зрения (героя, читателя) на исходную сюжетную ситуацию» $[12$, c. 56]. Еще одной важнейшей чертой новеллы является использование комического как «адекватной реакции на парадоксальность существования и торжества своевольной жизненной стихии над человеческими целями, планами и схемами» [12, с. 59].

В свете данного понимания новелла «Корень зла» представляет идеальный вариант новеллистической модели, поскольку, вопервых, в центре истории, составляющей ее сюжет, лежит как раз необычный случай, именно «казус», весьма сходный с анекдотом; во-вторых, есть новеллистический пуант финальная перемена точки зрения на исходную сюжетную ситуацию; в-третьих, доминантным является комический модус повествования.

Основу сюжета составляет поистине трагикомический случай. Группа пожилых людей небольшого немецкого городка, устав пить дома вино в полном одиночестве, по инициативе жены одного из выпивох, герра Шмидта, нашедшей союзницу в лице фрау Мюллер, «женщины решительного нрава» [6, с. 408], объединяется в своего рода мужской питейный клуб. Поочередно собираясь (каждый со своим вином) в чьем-либо доме, они постепенно обретают способность вести за выпивкой незатейливые разговоры о погоде, о видах на урожай, о прошедших событиях и т.п. Ежедневные мужские собрания дают их женам долгожданную возможность проводить в каком-нибудь другом доме свои посиделки за вязанием, разговорами о внуках и внучках, сдабривая их непременной чашечкой кофе.

Так удачно сложившаяся, к удовольствию мужей и жен, ситуация приобретает неожиданный поворот, приводящий к комическим и, в конечном итоге, комедийно-трагическим событиям. Случилось так, что мужчины, объединившись с целью совместных выпивок, категорически отказываются принимать в свой круг чрезмерно любопытного герра Пюклера, «маленького, вертлявого, кислого человечка, с косыми пронзительными глазками», которые «действовали как бурав» [6, c. 409] и вызывали у собеседника ощущение, что из его лба вот-вот «полетят опилки» $[6$, c. 409]. По этой причине мужчины решают встречаться «подпольно», в глубокой тайне в большом погребе герра Брауна, что и погубило их.

Трагикомической развязке предшествует череда то забавных, то смешных, то бурлескных происшествий. Отвергнутый «клубом» выпивох герр Пюклер устраивает за ними настоящую слежку, каждый вечер обходя дома всех членов клуба, но каждый раз его встречают закрытая дверь и темные окна. Обескураженный бесплодными поисками, он, в конце концов, является к начальнику полиции, внушая ему мысль о наличии в городке анархистского заговора. Он передает ему список имен шестерых «заговорщиков» (именно столько было членов клуба) и побуждает начальника начать расследование дела о «тайных сходках». И хотя последний и считает, что представленных в списке людей трудно заподозрить в заговоре ("they are not the kind of men I would suspect of plotting") [6, c. 411]), он уступает напористому герру Пюклеру и выделяет, как замечает автор, «без особого энтузиазма», полицейского для расследования этого дела.

Уже сама эта сцена являет собой яркий образец гриновского комизма, окрашенного насмешкой не только над незадачливым гер- 
ром Пюклером с его мстительным характером, прикрытым показной гражданской активностью, но и слушающим его полицейским чиновником. Приведем в качестве примера этот эпизод. Сообщив суперинтенданту, что в городе наблюдается разгул анархистских банд (an anarchist outrage) [6, с. 411]) и что даже поговаривают о покушении на великого герцога, он начинает сверлить своими глазами - буравчиками переносицу суперинтенданта, от чего тот начинает ерзать на стуле и у него начинается мигрень. И далее Грин через насыщенный насмешливостью диалог показывает, как здравомыслящий, но не желающий иметь неприятности суперинтендант постепенно уступает напористому герру Пюклеру с его навязчивой идеей тайного общества, которое существует под самым носом полиции ("under the nose of the police... there exists just such a society") [6, c. 411].

В столь же насмешливой манере, переходящей порой в бурлеск, описывается участие выделенного суперинтендантом бесхитростного полицейского. Он начинает его с прямого расспроса окружающих о шестерых подозреваемых, что побуждает последних к еще большей скрытности и осторожности. Все это в свою очередь влечет за собой целый ряд комических ситуаций.

Одна из них связана с планом маскировки питейного клуба. Чтобы скрыть место попоек, каждый вечер один из членов клуба должен был «приносить себя в жертву общему делу, отказываясь от участия в попойке, чтобы навести герра Пюклера и полицейского на ложный след» ("each one sacrificed a night's drinking in order to lead Herr Puckler and the policeman astray") [6, c. 411-412].

«Приносящим себя в жертву общему делу» однажды оказывается герр Шмидт, который решает увести герра Пюклера подальше от городка. Устав и желая передохнуть, он по ошибке попадает в публичный дом. Собираясь через какое-то время покинуть его, он обнаруживает, что находится под наблюдением полицейского, сменившего на посту герра Пюклера. Чтобы проскользнуть незамеченным, герр Шмидт вынужден переодеться в женское платье. Хозяйка заведения и девицы так обрядили и разукрасили его, что, когда он выходит на улицу, то видом своим настолько поражает полицейского, что тот, по словам автора, буквально прирос к месту ("the policeman was so astonished by the sight that he stood rooted to the spot") [6, c. 413].

И хотя герр Шмидт, обладавший, по замечанию рассказчика, фигурой «одной из своих винных бочек» [6, с. 417], вихрем проносится мимо полицейского, обмануть ему его не удается, и в своем рапорте суперинтенданту полицейский сообщает, что, "members of the secret siciety dressed themselves as women and in that guise freguented the gay houses of the town" [6, с. 413] («члены тайного общества переодеваются в женское платье и в таком виде посещают увеселительные дома городка»).

На недоуменный вопрос суперинтенданта, зачем они это делают, герр Пюклер намекает на разгул оргий, которые начали выходить «за рамки естественного положения вещей» ("which went beyond the natural order of things") [6, с.413], добавив при этом, что анархия охватила все, даже интимные отношения между мужчинами и женщинами ("anarchie... is out to upset everything, even the propet relationship of man and women") [6, c. 413].

Таким образом, безобидная со всех сторон затея шестерых горожан создать клуб совместных выпивок благодаря мстительной зависти и въедливого любопытства отвергнутого герра Пюклера обретает черты анархистского заговора, угрожающего государству и нравственным устоям общества. Гипертрофированная мнительность герра Пюклера начинает приобретать болезненные формы, порождая новые комические эпизоды, приводящие к печальному для него исходу.

Сперва он для скрытой охоты за неуловимыми «заговорщиками» начинает появляться в женских одеждах, подозревая каждую полную женщину в том, что это один из переодетых «заговорщиков», и доходит до того, что с одной из них срывает парик, вызывая публичный скандал.

Затем под видом кухарки, которую герр Браун (владелец погреба клуба) неосторожно заказал в местной газете для приготовления пончиков с мясом для вечерних посиделок, проникает в самое сердце заговора и представляет суперинтенданту записанный дословно совершенно пустой и тягучий разговор шестерых выпивающих мужчин. 
Донос, озаглавленный как «К Делу О Тайных Сходках В Погребе Герра Брауна на ... Штрассе, 27», содержал 12 страниц полилога, состоящего из нейтральных реплик так называемых заговорщиков, перемежаемого долгими паузами: о дожде, о видах на урожай винограда; о почтальоне, чуть не сломавшем ногу; о спешащих городских часах; о собаке бургомистра с черными пятнами на спине и т.п.

Этот бессмысленный донос и нелепые попытки расшифровать его как подготовку к теракту [6, с. 414-415] - еще один образец гриновского комизма, сильная сторона которого, по мнению Пико Айвэ, коренится в «нюансах» и в умении сплавлять воедино комедию и драму человеческого бытия [11].

В насмешливом ключе описана и смерть герра Пюклера. Не зная о своем разоблачении, он является с ангажированным для более полного сбора сведений переодетым в женское платье полицейским, которого собирается представить как своего помощника, и погибает от попавшего ему в голову ночного горшка, брошенного одним из рассерженных заговорщиков.

Это своего рода первый уровень комизма, возникающий в рассказе отца. Но поскольку новелла построена как рассказ в рассказе: историю, рассказанную отцом, передает его сын и сопровождает ее своими комментариями, возникает второй уровень комизма, выдержанный в основном в добродушноюмористической тональности.

Рассказанная отцом история давнего события в немецком городке, где он когда-то жил до переезда в Англию, подается как моральное поучение своему сыну - школьнику, а каждый эпизод этой истории - красочная иллюстрация одного из смертных грехов с целью предостеречь от них подростка. Комизм здесь рождается из контраста забавности происходящего и серьезности выводов морально-религиозного плана, которые отец хочет внушить сыну.

Эту неувязку и подчеркивает ныне уже взрослый повествователь, который передает некогда рассказанную отцом историю. В структурно-композиционном плане ему принадлежит начало новеллы, краткие замечания, комментирующие рассказ отца, и финал. С мягким юмором, в котором сквозит явная симпатия, он характеризует своего отца как «человека безупречной нравственности», искреннего в своей вере протестанта, большого «ревнителя веры без всяких колебаний и сомнений» [6, с. 407], и не без лукавства добавляет, что «есть все основания полагать, что эта высокая добродетель стала нашей фамильной чертой» [6, с. 407].

Вступлением к рассказу отца, сообщает далее повествователь, всегда была фраза о том, что первородный грех научил людей скрытности и что если человек скрытничает, то рано или поздно он впадает в грех. Поучительным примером-иллюстрацией и был, по мнению отца, как раз упомянутый выше клуб Шмидта, при создании которого мужчины прибегли к конспирации, то есть к скрытности.

А далее следует комментарий повествователя, ставящий под сомнение вывод отца о первом грехе ("... and from secrecy, my father would moralize, you can grow every sin in the calendar. I pictured secrecy like the dark mould in the cellar where we cultivated our mushrooms, but the mushrooms were good to eat, so that their secret growth... I always found an ambivalence in my father's moral teaching") [6, с. 410] («... а от скрытности, морализовал, бывало, мой отец, как тебе известно, произрастает всякий грех. Мне лично скрытность представлялась чемто вроде заплесневелой темноты в нашем погребе, где мы выращивали грибы, но грибы были хороши для еды, хотя и выращивались в укрытии... Я всегда находил двусмысленность в отцовских нравоучениях»).

Невольное пребывание герра Шмидта в публичном доме, где он всего лишь укрывался от назойливого преследования герра Пюклера, отец оценивал как второй грех - грех прелюбодеяния. Краткий комментарий повествователя к этому примеру-иллюстрации очередного греха является мягким, но явным опровержением отцовской оценки. Он пишет: «И вот так скрытность, говорил мой отец, породила второй грех», и добавляет: «Однако же он не закончился ложью и прелюбодеянием» $[6$, с. 412]. То есть повествователь сомневается, можно ли это назвать грехом, тем самым подчеркивая сомнительность суждений отца.

Подобные замечания сопровождают и другие комически представленные эпизоды отцовской истории. Так, эпизод посещения магазина женской одежды герром Пюклером для 
экипировки тучного полицейского оставляет повествователя в недоумении, к какой категории относит его отец этот грех, поскольку ранее уже были грехи лжи и прелюбодеяния.

Эпизод о слухах, которые поползли по городу о герре Пюклере после этого случая и которые, по убеждению отца, были иллюстрацией греха злословия, повествователь сопровождает лишь замечанием о вероятности этого греха. По поводу же догадок, сопровождающих эти слухи и означавших в отцовском перечне очередной грех, повествователь замечает ("So this it was, my father would say, that foul talk was added to the other sins of lies, fornication, scandal") [6, c. 417] («Вот так оно и было, говаривал мой отец, сплетня добавилась к другим грехам - лжи, прелюбодеянию и злословию. Но самый тяжкий из всех грехов был еще впереди»). Им, как считал отец, была смерть герра Пюклера, которую он расценивал как убийство, хотя длившийся семь месяцев суд и оправдал всех шестерых членов клуба.

Юмористически окрашенный комментарий к этому греху, завершающий новеллу, в очередной раз подчеркивает двуплановость нарратива. Он заслуживает быть приведенным полностью. После сообщения об оправдании причастных к смерти герра Пюклера автор пишет: «Но есть высший суд, - всегда говаривал мой отец, завершая свой рассказ, и в этом суде грех убийства никогда не остается без возмездия. Ты начинаешь со скрытности (и он смотрел на меня так, словно знал, что мои карманы набиты ею, как оно и было, включая записку, которую я собирался передать завтра в школе рыжеволосой девчонке во втором ряду) и ты заканчиваешь всеми грехами на свете». И для моего блага он начинал перечислять их от начала до конца: ложь, пьянство, прелюбодеяние, злословие, убийство и превышение власти

- Превышение власти?

- Да, утверждал он, пристально глядя на меня сверкающими глазами

Я думал, что он имел в виду суперинтенданта и фрау Пюклер (которые тайно обручились после смерти герра Пюклера. - прим. автора). Но тут он достигал кульминационного момента: «Мужчина в женской одежде - это страшный грех Содома».
После этого сразу следует новеллистический пуант, завершающий историю и создающий финальную перемену точки зрения на исходную сюжетную ситуацию. Напомним, что исходной ситуацией этой истории является поучение отца о том, что скрытность является отправным моментом любого греха.

Финальная же фраза отца опровергает его спорное утверждение и, по сути, разрушает все так, казалось, логично выстроенное наставление. Услышав о страшном грехе Содома, подросток, сгорая от любопытства, спрашивает: «А что это такое?» И в ответ слышит: «Есть вещи..., которые родители должны скрывать от детей твоего возраста» [6, с. 419].

Таким образом, оригинальное сюжетнокомпозиционное построение новеллы, которое заключается в наличии двух повествователей и двух эксплицитных точек зрения на одну и ту же историю - точки зрения рассказчика-отца и точки зрения повествователя - сына, пересказывающего и комментирующего ее по истечении значительного времени, включает дополнительные механизмы комизма и расширяет смысловое пространство новеллы.

За счет доминирующей двойной фокализации создается своего рода два уровня комизма. С одной стороны, это комизм забавности самой истории и нелепых ситуаций, возникающих по ходу ее развертывания. Этот комизм усиливается действиями и рассуждениями других актантов этой истории (герр Пюклер, суперинтендант, герр Шмидт и члены мужского клуба, жена герра Пюклера и жена герра Шмидта).

С другой стороны, это комизм, создаваемый комментирующим пересказом этой истории повествователем и его скептическим отношением к наставительно-религиозным поучениям, которые первый рассказчик старается извлечь из нее. Благодаря использованию этого приема нравоучительная история религиозной направленности предстает как анекдотически-забавный случай.

\section{выводы}

Выполненный анализ short story The Root of All Evil Грэма Грина позволяет сделать следующие выводы. Данное произведение по своей жанровой природе является новеллой, 
а не рассказом, как в дефинициях французской и русскоязычной критики. Об этом свидетельствует наличие таких жанровых новеллистических признаков, как необычное происшествие, забавный случай, «казус», лежащий в основе новеллы; динамизм развертываемых событий и наличие одной сюжетной линии; неожиданный сюжетный поворот (пуант) и присутствие более ли менее ярко выраженного комического начала.

Являясь формой художественного познания бытия, жанр задает и специфику художественного миромоделирования (тип эстетического отношения к действительности, масштаб ее охвата, композиционную структуру, тип мышления).

Структура и смысловое содержание произведения The Root of All Evil отвечает художественной модели именно новеллистического жанра. Безобидный по своей сути случай, ко- торый ортодоксальный «ревнитель веры без всяких колебаний и сомнений», старается превратить в поучительную историю о всех смертных грехах, в конечном итоге превращается в забавную историю о цепи комических и трагикомических происшествий, вызванных желанием группы мужчин создать своего рода питейный клуб.

Использование Грином комического модуса повествования позволило ему легко и непринужденно, но довольно эффективно высмеять издержки религиозного догматизма, готового объявить греховными самые естественные привычки и потребности людей.

Использованная в работе методика представляется перспективной как для дальнейшего изучения малой прозы Грэма Грина, так и для аналогичных сфер исследования.

\section{СПИСОК ИСПОЛЬЗОВАННЫХ ИСТОЧНИКОВ / REFERENCES}

1. Bibihin, V. (1990). Begstvo Grjema Grina [Graham Greene's flight]. Retrieved August 1, 2018, from http://www.bibikhin.ru/begstvo_graham_green (in Russian) [Бибихин, В. (1990). Бегство Грэма Грина. Актуально на 01.08.2018. URL: http://www.bibikhin.ru/begstvo_graham_green].

2. Greene, G. (1963). Poslednij shans mistera Livera [A Chance for Mr Lever]. Moscow: Pravda (in Russian)

[Грин, Г. (1963). Последний шанс мистера Ливера. Москва: Правда].

3. Greene, G. (1967). Poezdka za gorod [A drive in the country]. Moscow: Pravda].

[Грин, Г. (1967). Поездка за город. Москва: Правда].

4. Greene, G. (1994). Twenty-one stories. London: Penguin Books.

5. Greene, G. (1995). Collected Short Stories. London: Penguin Books.

6. Greene, G. (2005). Complete short stories. New York: Penguin.

7. Greene, G., Sibon, M., Gallix, F., \& Philippe, I. D. (2013). Nouvelles complètes. Paris: Robert Laffont

8. Guseva, E. (1957). Vmesto predislovija [Instead of introduction]. In G. Grin, The Basement Room (p. 5-9). Moscow: Iskusstvo (in Russian)

[Гусева, Е. (1957). Вместо предисловия. В Г. Грин, Комната для живых (с. 5-9). Москва: Искусство].

9. Ivasheva, V. (n. d.). Protivorechija Grjema Grina [Graham Greene's Contradictions].Retrieved August 1, 2018, from http://detectivemethod.ru/english/contradictions-graham-greene/ (in Russian) [Ивашева, B. (n. d.). Противоречия Грэма Грина. Актуально на 01.08.2018. URL: http://detectivemethod.ru/english/contradictions-graham-greene/].

10. Ivjanskaja, I.S. (1989). Predislovie [Introduction]. In G. Greene, A Chance for Mr Lever (p. 3).

Moscow: Vysshaja Shkola (in Russian)

[Ивянская, И.С. (1989). Предисловие. В Г. Грин, Последний шанс мистера Ливера (с. 3).

Москва: Высшая Школа].

11. Iyer, P. (2005). Introduction. In G. Greene, Complete short stories (pp. VII -XVII). New York: Penguin. 
12. Tamarchenko, N. D. (Ed.). (2012). Teorija literaturnyh zhanrov [Theory of literary genres] (2nd ed.). Moscow: Akademija (in Russian)

[Тамарченко, Н. Д. (Ред.). (2012). Теория литературных жанров (2-е изд.). Москва: Академия]. 